\title{
USING THE MIN/MAX METHOD FOR REPLENISHMENT OF PICKING LOCATIONS
}

\author{
Raitis Apsalons ${ }^{1}$, Gennady Gromov ${ }^{2}$ \\ Transport and Telecommunication Institute, \\ Transport and Logistics Department \\ Lomonosova 1, Riga, Latvia \\ ${ }^{1}$ Ph.: +371 26527874, e-mail: raitis.apsalons@inbox.lv \\ 2Ph.:+37129169056,e-mail: gromov@tsi.lv
}

\begin{abstract}
The irregularity of removing quantities from a definite picking location in a warehouse very often results in the stock out in the particular picking address. In practice, the Red Card principle is used to determine a critical level for each picking location when it is necessary to start the replenishment of stock in the picking address. The question is how to calculate an adequate critical level. The guidelines in this paper explain in detail the solution of the problem using the Min/Max stock control method and mathematical algorithms adjusted by authors. In order to check the validity of these mathematical algorithms of the Min/Max method, the simulation modelling has been also done and presented.
\end{abstract}

Keywords: Min/Max method, replenishment of items, red card principle, picking process, picking locations

\section{Introduction}

Picking of goods according to customers' orders is the one of the most complicated warehousing processes. Picking of goods is most expensive warehouse operation: $50 \%-55 \%$ from total warehouse operations cost (Sangam, 2010). In practice, in a warehouse, 2 picking systems of physical flow of goods are used: either $\mathrm{M} 2 \mathrm{G}$ - man to goods system or G2M - goods to man system. The last one demand automated systems to be in place for sorting items during the picking process or after the picking process is completed. In this paper authors have provided an overview of the system $\mathrm{M} 2 \mathrm{G}$ when the picking process is realized by pickers - workers and adjusted picking technology. Order - picking time for M2G consists of travelling (55\%); of searching (15\%); of extracting of goods (10\%) and of paperwork or other activities (20\%) (Frazelle, 2002). From the point of view of picking organization, selecting of goods can be provided:

- Right from the storage area (SA) in the warehouse, there is no special picking area for handling units (HU) and customer units $(\mathrm{CU})$, in this case full pallets or $\mathrm{HU}$ and $\mathrm{CU}$ are selected from SA.

- $\quad$ From separate SA - full pallets and from separate picking area (PA) - HU and CU.

- From SA - full pallets and from PA - HU and CU in case that PA is involved in SA, for example, the first two levels of one row rack storing system is as PA, but the remaining higher levels are as SA.

This paper deals with the analysis of the 3-rd picking organization system.

Another important aspect is the replenishment process of picking addresses - how often quantities of any item are moved from SA to PA. In this content we assume that the replenishment of definite address is provided once the stock of definite items is below the critical level, which is called a minimum. The irregularity of removing amounts from definite picking locations in a warehouse very often results that the stock out occur in this picking address (Lukinskiy and Lukinskiy, 2016).

The main purpose of paper is to develop Min/Max stock control model for replenishment of a picking location. Hypothesis - to prove (confirm) that using the Min/Max method for replenishment of a picking location is a sufficient measure for the stock - out of definite items not to occur. However, this is a special case, because the logistics theory and modern bibliography describes the Min/Max method as an inventory stock control method for procurement of goods (Praude, 2013; Vermorel, 2009; Ballou, 1999). The classic Min/Max inventory control method is based on variability in demand (King, 2011), and the forecasts are implicitly defined through replenishment rules (Vermorel, 2012). But, the main issue, given by authors, is to prove that the Min/Max stock control method is appropriate for an uninterrupted picking process in the warehouse. Besides, it is necessary to take into account that picking quantities of definite items in equal time intervals are irregular. 
Consequently, the definition of the scientific problem is to provide the availability of stock for each stock keeping unit (SKU) in picking faces within an uninterrupted picking process. The object of the research concerns the interconnection of a replenishment process with the picking process. The subject of the research the replenishment models of picking faces for providing an uninterrupted picking process.

\section{Restrictions of the Research and Irregularity of Picking Quantities from Each Picking Location}

The main restrictions of the research are the following. There is one row rack storing system available in the definite warehouse. Each item is placed on a separate pallet. Let it be physical picking system: walk and pick (Tomkins et al., 2003). For this purpose a picking area (PA) is established in this warehouse. The picking process will be realized by picking handling units (HU) and customer units (CU). Therefore, the ground and first levels of pallet racks are used as PA. The picking location of each item consists of 2 pallets: 1 pallet on the ground level and the other on the first level of the rack. It is defined that the replenishment - moving the item from the storing area (SA) to PA will occur if the stock of definite items in the picking location reaches the critical level (Ruehrdanz, 2016). This approach is called the Red Card principle (RCP) of picking systems (Apsalons, 2012). However, some difficulties will appear using the RCP: it is not easy to determine the amount of each item which is appropriate to signal the necessity of replenishment once again. This is due to the irregularity of removing quantities of HU and CU from each location (Koster, 1999). Figure 1 illustrates the picked quantities of definite items per each time interval which consists of 10 minutes $\left(Q_{i k} P A\right)$ from PA. The figure shows that the quantities of the specific item per each time interval are different. It means that in a picking process, picked quantities of specific items at definite picking address diminish the available stock in various speeds. The question to consider is how to calculate the adequate critical level at which the replenishment needs to be started to avoid a stock out situation to occur in a picking process.

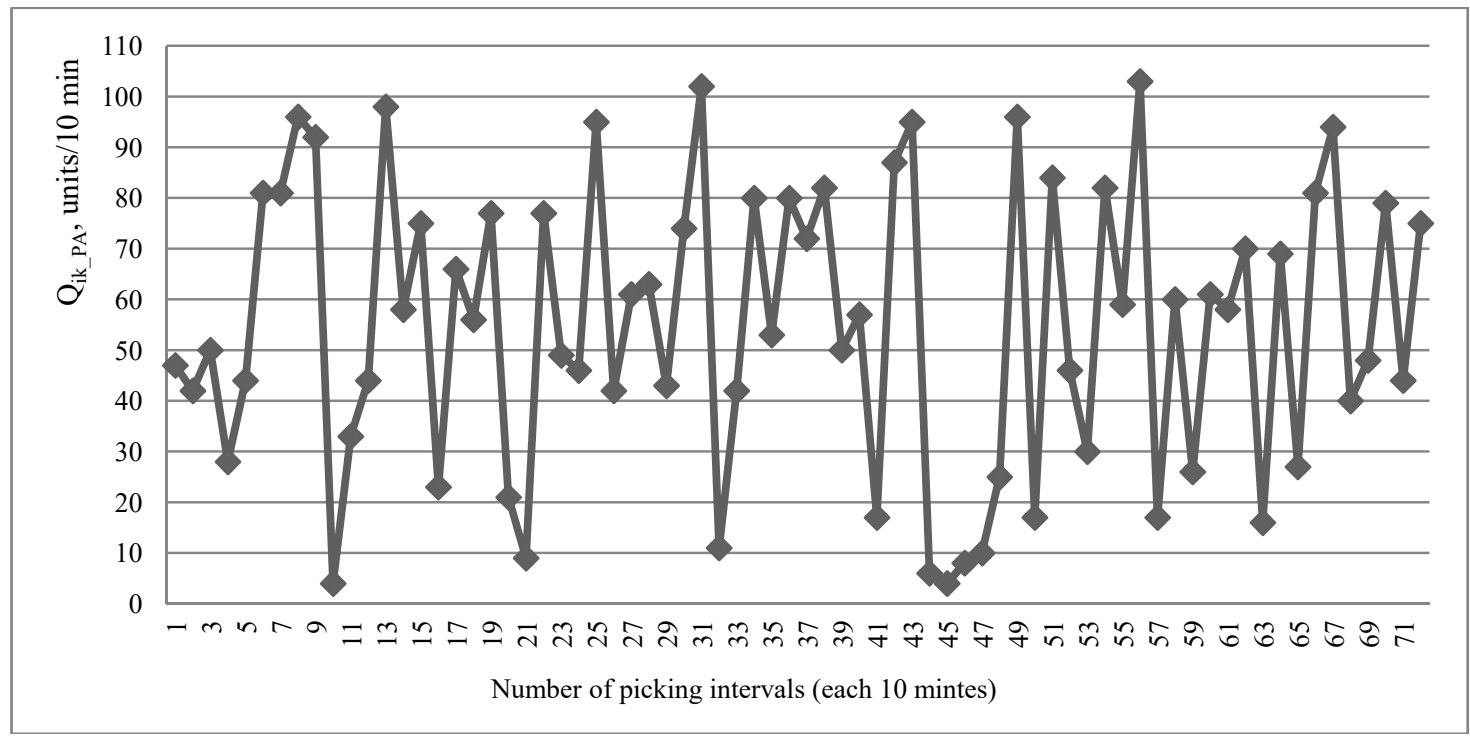

Figure 1. Example of uncertainty of picking quantities in picking time interval, picked units per 10 minutes from one definite picking address

A solution for the described above issue is the use of Min/Max stock control method for ensuring of which refers to inventory replenishment in a picking locations (Vermorel, 2009). For this purpose the RCP may serve for determining a certain critical level or signal for launching a replenishment process in a warehouse management system. When stock of item at a picking address falls below the critical level then the replenishment will immediately occur. Besides, due regard should be paid to the fact that the Min/Max stock control method is a pull - down strategy (Praude, 2013; Ballou, 1999). This implies that the replenishment of each item will be realized at different instants of time, namely, exactly when the stock level is lower than the critical level (Frazelle, 2002). An optimal application of the RCP will guarantee $100 \%$ stock availability in an uninterrupted picking process without an occasion of stock - out of any item. The authors of this research have proved that the use of Min/Max method for replenishment of picking locations is a sufficient and appropriate measure for a stock - out of items in picking addresses not to occur. 


\section{Description of the Task to be Solved by Min/Max Replenishment System for a Single SKU}

To suppose that the warehouse has received a certain number of orders per day in the warehouse management system (WMS) for delivery on the next day, each order: $\mathrm{O}_{1} ; \mathrm{O}_{2} ; \ldots$; $\mathrm{O}_{\mathrm{N}}$. The receiving process of orders is realized until a definite time moment (TM) is reached (for example, TM=12 o' clock). After that the receiving process of orders is closed by warehouse clerk or clients' service specialist. Then the deliveries of orders, incoming into the system after TM, will be provided on the next day.

The principle of division of orders (PDO) states that quantities $Q_{i k}$ for definite SKU of each order are divided into 2 parts (where $\mathrm{k}$ is a definite SKU):

- $\quad$ For picking full pallets from SA: $Q_{i k_{-} S A}$ (expressed in customer units from SA).

- For picking handling units and customer units (HU+CU) from PA: $Q_{i k_{-} P A}$ (expressed in customer units from PA).

Therefore, quantities for one definite SKU of a single order are usually expressed as follows:

$Q_{i k}=Q_{i k_{-} S A}+Q_{i k_{-} P A}$.

Since the issue under consideration in the research is the picking area and replenishment of a warehouse, the further analysis will focus on the quantities of SKU collected in PA $\left(Q_{i k_{-} P A}\right)$, assuming that there are no obstacles for stock in full pallets in the SA:

$\sum_{i=1}^{N} Q_{i k_{-} P A}=\left(\begin{array}{c}Q_{1 k_{-} P A} \\ Q_{2 k_{-} P A} \\ \ldots . \\ Q_{N k_{-} P A}\end{array}\right)$.

To assume $100 \%$ stock availability for orders picked from SA and for replenishment to be provided from SA to PA.

The PA consists of picking addresses: definite locations for each SKU. To assume that for each SKU is one single picking location. It means that before the picking process starts, one single SKU will have a single picking location and definite quantity of stock in this location: $S_{k}$.

Having divided the picking process of a day by time intervals $\Delta$ t, the number of time intervals is $\mathrm{z}$, and the picked different quantities of definite SKU in each time interval can be expressed as follows:

- For duration of the first time interval: $t_{1} \rightarrow Q_{t 1 k_{-} P A}$.

- For duration of the second time interval: $t_{2} \rightarrow Q_{t 2 k_{-} P A}$.

- $\quad$..........

- For duration of the last time interval: $t_{z} \rightarrow Q_{t z k_{-} P A}$.

The sum of the SKU quantities collected during the picking intervals in PA $\left(\mathrm{F}_{\mathrm{k}}\right.$ - picking flow of single SKU) is equal to the sum of definite SKU quantities of all orders within a day:

$\mathrm{F}_{\mathrm{k}}=\sum_{h=1}^{Z} Q_{t h \_P A}=\sum_{i=1}^{N} Q_{\mathrm{ik}_{-} \mathrm{PA}}$.

Since the stock quantities in each picking address are limited there is a risk to the time period of stock - out to be reached in case where:

$\sum_{i=1}^{N} Q_{i k_{-} P A}>\mathrm{S}_{\mathrm{k}}$, in other expression: $\mathrm{F}_{\mathrm{k}}>\mathrm{S}_{\mathrm{k}}$.

In practice, the situation of stock - out should be eliminate in order to prevent the waste of additional picking time, additional labour cost and longer picking process time. Therefore, it is important to estimate the RCP - Red Card Principle of replenishment - critical stock balance of a single SKU picking location: $S_{w k}$ - the quantity of warehouse stock in a picking location of definite SKU, when the stock drops lower than $\mathrm{MIN}_{\mathrm{k}}$ (Fig. 2, point 2).

Thus the time interval of replenishment $t_{r k}$ is obtained, which corresponds to the stock balance after the time interval when replenishment has been started:

$t_{r k} \rightarrow S_{k}-Q_{t 1 k_{-} P A}-Q_{t 2 k_{-} P A}-\cdots \ldots-Q_{t r k_{-} P A}=S_{w k}$, and $\mathrm{S}_{\mathrm{wk}}>0$, but $\mathrm{S}_{\mathrm{wk}}<\mathrm{MIN}_{\mathrm{k}}$,

where: $t_{\mathrm{rk}}$ - time moment, when the quantities of definite SKU in the definite picking location fall below $\mathrm{MIN}_{\mathrm{k}}$.

A critical stock level of each SKU can be calculated as thus: 
$\operatorname{MIN}_{k}=Q_{a} \cdot\left(R_{p}+\Delta \mathrm{t}\right) \cdot\left(1+k_{S S}\right)$,

where: $\mathrm{Q}_{\mathrm{a}}$ - calculated average quantity picked per one time interval $\Delta \mathrm{t}$;

$\mathrm{R}_{\mathrm{p}}$ - number of time intervals for replenishment (depends on the average distance between PA and SA for replenishment, and additional processes to realize replenishment in the WMS).

$k_{s S}$ - coefficient of safety stock (King, 2011) in case where over the time period $\mathrm{R}_{\mathrm{p}}$ the picking quantities exceed $\mathrm{Q}_{\mathrm{a}}$ to ensure $100 \%$ stock availability (service level: $\mathrm{SL}_{\mathrm{k}}=100 \%$ ).

Since the receiving process of orders has been realized until a definite time moment TM is reached, the picking flow of single SKU $\left(F_{k}\right)$ will be known. Then the flow distribution of picking if a single SKU will be also known between minimum quantity $\left(Q_{\text {minim }}\right)$ and maximum quantity $\left(Q_{\text {maxim }}\right)$ of picking in time interval $\Delta \mathrm{t}$ as well as. After that $\mathrm{Q}_{\mathrm{a}}$ can be calculated. The coefficient of safety stock can be obtained as maximum deviation divided by calculated average quantity picked per one time interval $\Delta \mathrm{t}:$

$\mathrm{k}_{\mathrm{ss}}=\left(\mathrm{Q}_{\text {maxim }}-\mathrm{Q}_{\mathrm{a}}\right) / \mathrm{Q}_{\mathrm{a}}$.

$R_{p}+\Delta \mathrm{t}$ means that an additional interval is needed because the stock balance of SKU in the specific picking location maximum could be the one time interval under minimum (to avoid stock - out and to provide stock availability 100\%) (Fig. 2).

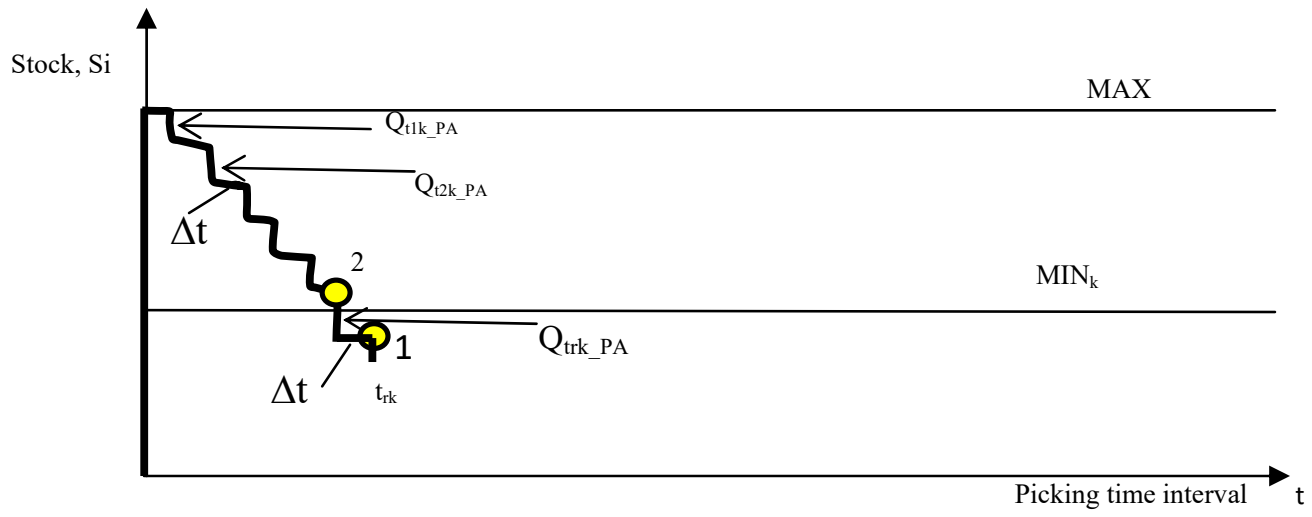

Figure 2. Replenishment time moment $\mathrm{t}_{\mathrm{rk}}$

Thus for replenishment time moment $t_{r k}$ can be determined, i.e., right when the replenishment starts.

$\mathrm{S}_{\mathrm{k}^{-}} \sum_{h=1}^{Z} Q_{t r k_{-} P A}<M I N$ (for point 1 ),

$\mathrm{S}_{\mathrm{k}^{-}} \sum_{h=1}^{Z} Q_{t r k+1_{-} P A} \geq M I N$ (for point 2),

where: $\sum_{h=1}^{Z} Q_{\text {trk }_{-} P A}$ - sum of picked quantities after that stock quantity is less than MIN (the first point in the Figure 2); replenishment is going to realized;

$\sum_{h=1}^{Z} Q_{t r k+1_{-} P A}$ - sum of picked quantities in the time interval before replenishment that stock quantity is equal or more than MIN (the first point in the Figure 2); replenishment is not realized.

\section{Mathematical Modelling and Algorithms of Min/Max Method}

In order to demonstrate that the Min/Max stock control method in this case is applicable, the mathematical modelling and algorithms have been adjusted by authors in the MS Excel format. In the logistics theory the Min/Max method has 2 variants (Praude, 2013; Ballou, 1999):

- The Min/Max method expressed with fixed order quantity (variant 1). 
- The Min/Max method expressed with different order quantity (variant 2), which is difference between level MAX and q - quantity of stock once the stock balance is lower than level MIN, e.i., the quantity of each following replenishment is different.

In this research, for the picking process and use of RCP, these systems depend on the replenishment volume of each item. In case of the first variant of Min/Max method, the replenishment quantity each time is exactly one pallet as the picking address consists of two pallets, while for the second variant of Min/Max method the replenishment quantity exceeds one pallet and it varies each time.

Both variants of the Min/Max method have been adjusted for the RCP, and it consists of the following parameters and algorithms.

The first one is the MIN - minimum - the stock level which appears if the stock balance in a picking address is lower than the minimum stock level, and the replenishment of this picking address will be accordingly realized, or stated another way, the RCP will occur in the Warehouse Management System. For both variants the MIN is expressed by formula (6).

The second one is the MAX - a minimal stock level which is allowed to determine the correct quantity of replenishment of picking address:

- For variant 1:

$\mathrm{MAX}=2 * \mathrm{MIN}$.

- For variant 2:

$\mathrm{MAX}=2 * \mathrm{Q}_{\mathrm{pll}}$,

where: $\mathrm{Q}_{\mathrm{pll}}-$ the quantity of full euro pallet (units/pall).

The third parameter is SS - the quantity of safety stock used for uncertainty of picking flow $\mathrm{Q}_{\mathrm{ik} \text { PA }}$ from picking address during the replenishment time interval and it is adequate for both variants:

$\mathrm{SS}=Q_{a} \cdot\left(R_{p}+\Delta \mathrm{t}\right) \cdot k_{s S}$.

The next one is the $\mathrm{Q}_{\mathrm{s}}$ - the quantity of the stock at the beginning is equal to 2 full euro pallets, because picking address consists of ground level and level 1 of the pallet rack and it is adequate for both variants:

$\mathrm{Q}_{\mathrm{s}}=2 * \mathrm{Q}_{\mathrm{pll}}$.

The last one is the $Q_{j}$ - the quantity of the each following replenishment of picking address:

- For variant 1 it responds to one full pallet:

$\mathrm{Q}_{\mathrm{j}}=\mathrm{Q}_{\mathrm{pll}}$.

- For variant 2 - the quantity of each following replenishment of picking address which is difference between the level MAX and $\mathrm{q}$ - quantity of stock once the stock balance is lower than level MIN:

$\mathrm{Q}_{\mathrm{j}}=\mathrm{MAX}-\mathrm{q}$.

Both the Min/Max stock control variants are appropriate solutions for the determination of a critical stock level when replenishment needs to be started (for RCP).

\section{The Simulation Modelling for Validity Control of Min/Max Method}

The methodology of the research consists of 5 steps to be implemented:

- To accept the inbound data of picking quantities per each 10 minutes per definite item in a definite fluctuation diapason: with a minimum and maximum fluctuation value.

- To calculate safety stock according to the replenishment time period in the MS Excel format.

- To develop the Min/Max method in MS Excel format, including the parameters of both variants of the Min/Max method and figures of stock balance at the start and at the end of picking time intervals, including the replenishment quantities.

- To apply variable quantities to the picking quantities flow for each time interval, using data simulation (Andriansyah et al., 2009) (Monte-Carlo simulation) in MS Excel format developed by authors. 
- To verify the mathematic algorithms and Min/Max method so that no stock - out situation occurs.

The mathematic algorithms of both variants of Min/Max method, adjusted by authors, must be verified by practical data. At this point a question appears: whether the mathematic algorithms of Min/Max method satisfy the condition of stock availability of definite items if the irregularity of picking quantities per definite time interval exists. Therefore, at first, it is necessary to obtain the data of picking quantities per each 10 minutes per definite item (Fig. 1). There are 2 variants to receive the inbound data:

- By using previous data - available statistical data of picking of definite items, thus the determination of a fluctuation diapason appears to have no difficulties.

- By using the data simulation generating the numbers of probability based on Monte - Carlo Simulation, the fluctuation diapason is assumed.

In this case study, the simulation modelling is used to check the system as a whole. To suppose that the minimum quantity of picking of a definite item per one time interval (per each 10 minutes) is 8 units, but the maximum quantity is 106 units. Consequently, it results in different picking quantities per each time interval with fluctuation between 8 units and 106 units. Thereafter, by using these input data and mathematic algorithms, the parameters of the Min/Max methods' variant 1 and the Min/Max methods' variant 2 are calculated. Besides, the coefficient of safety stock $\mathrm{k}_{\mathrm{SS}}$, which shows the irregularity of removing amounts $\mathrm{Q}_{\text {ik_PA }}$ from the picking address, satisfies the condition that in an uninterrupted picking process $100 \%$ stock availability is guaranteed.

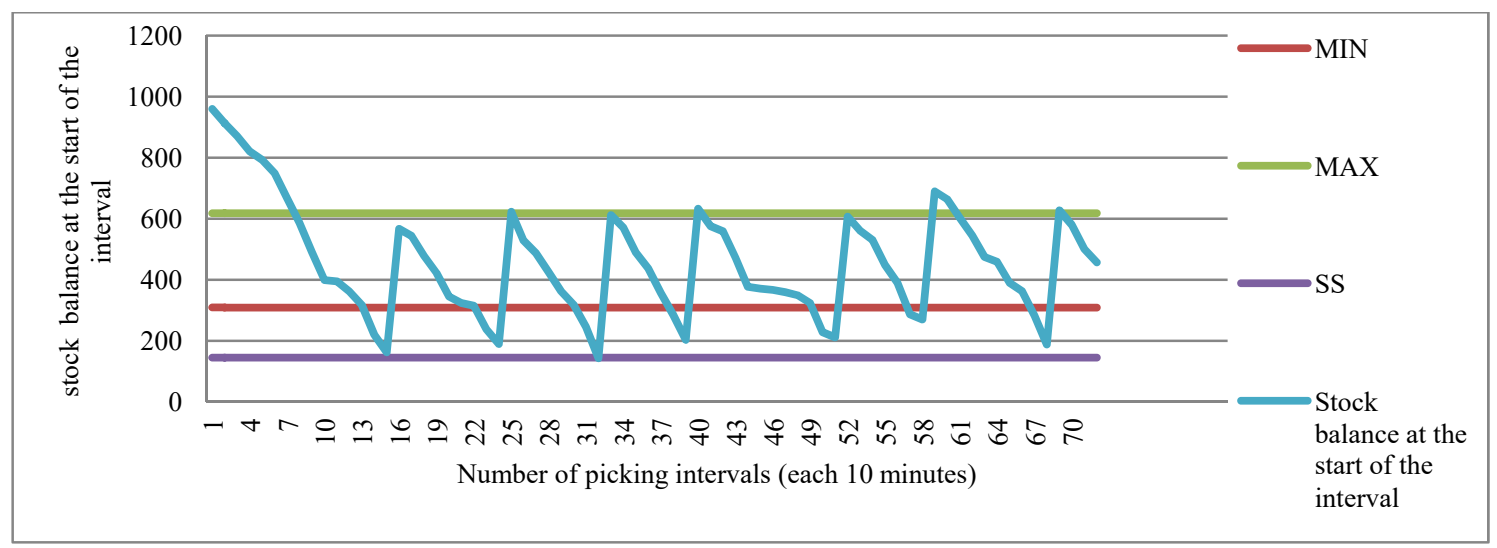

Figure 3. Stock balance at the start of the interval using the Min/Max stock control variant 1

The simulation modelling for the Min/Max stock control variant 1 shows that in this case the necessary quantity of SKU replenishment is equal to 1 pallet. The each replenishment of the quantity of SKU shows exactly the same (constant) pattern. Therefore, the stock balance at the start of the interval exceeds the level MAX (Fig. 3).

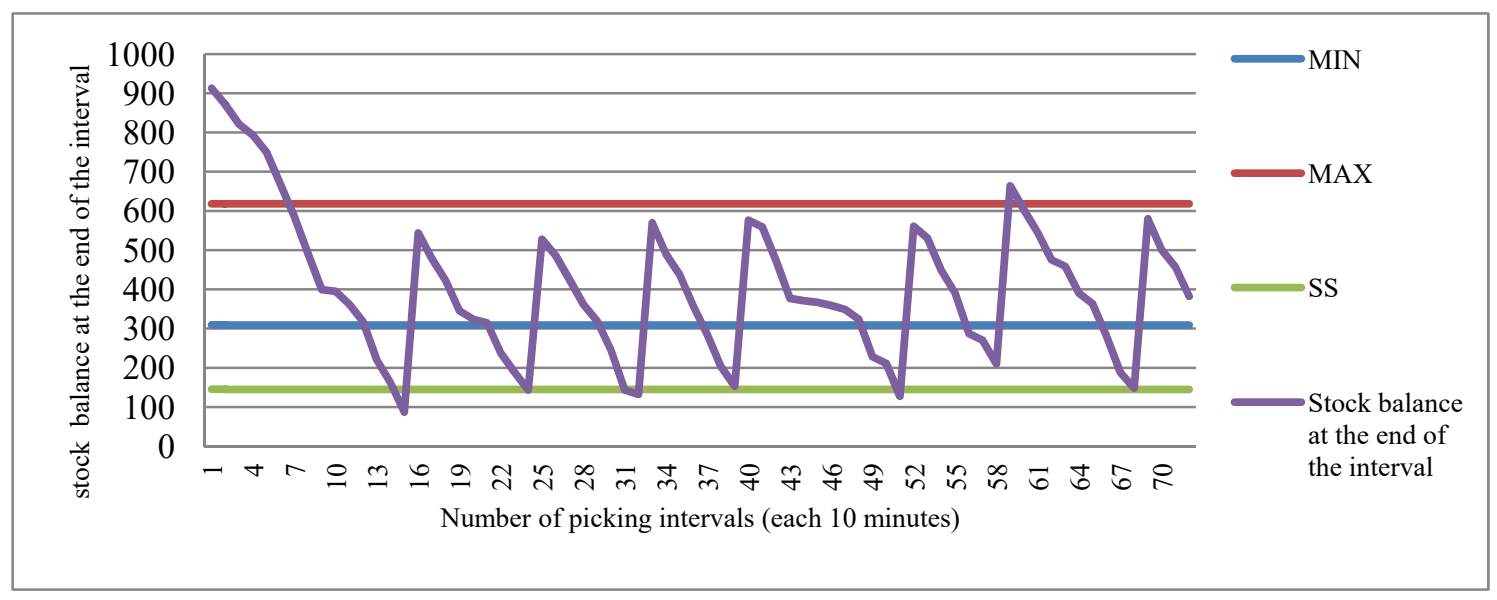

Figure 4. Stock balance at the end of the interval using the Min/Max stock control variant 1 
In the first cycle of time when the stock balance at the start of the time interval is lower than level MIN, the replenishment has been realized. The signal of RCP is transferred from the WMS (Warehouse Management System) in order to ensure the replenishment of the picking address to be started. This is an ongoing process during the whole day until the picking process is finished.

However, in order to make sure that the stock quantities are sufficient and the parameters of Min/Max variant 1 work adequate, verification is carried out by changing the picking flow quantities. This implies that the stock balance at the end of a time interval (Fig. 4) also needs to be checked because occasionally, at the start of the time interval, there is some added quantity of replenishment, too. The results of the simulation modelling illustrate the balance of stock at the end of the time interval is sufficient and no stock outs occur.

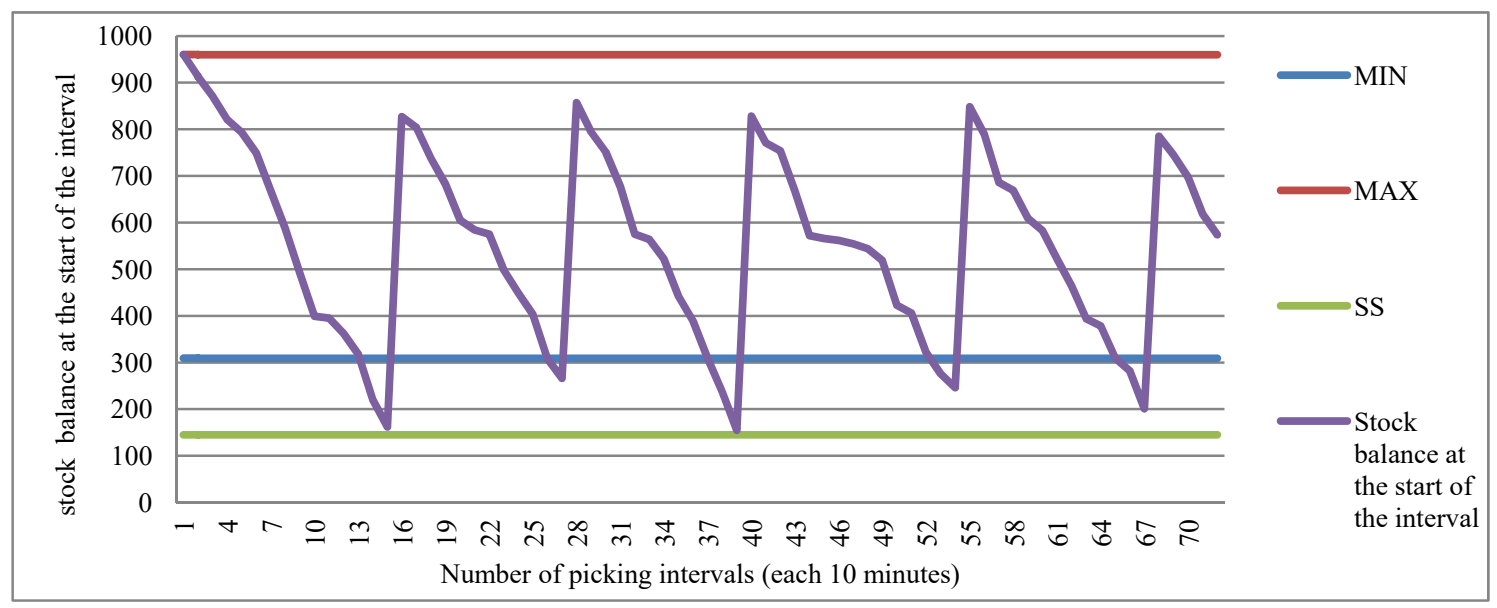

Figure 5. Stock balance at the start of the interval using the Min/Max stock control variant 2

The simulation modelling for the Min/Max stock control variant 2 shows that in this case the necessary quantity of SKU replenishment exceeds 1 pallet. The each replenishment of the quantity of SKU appears to be different (not constant). However, the stock balance at the start of the interval is lower than the level MAX (Fig. 5). Usually, the stock balance is not higher than the level MAX. There is only one exception: the quantity of stock is equal to the level MAX if no picks are realized at the time of replenishment.

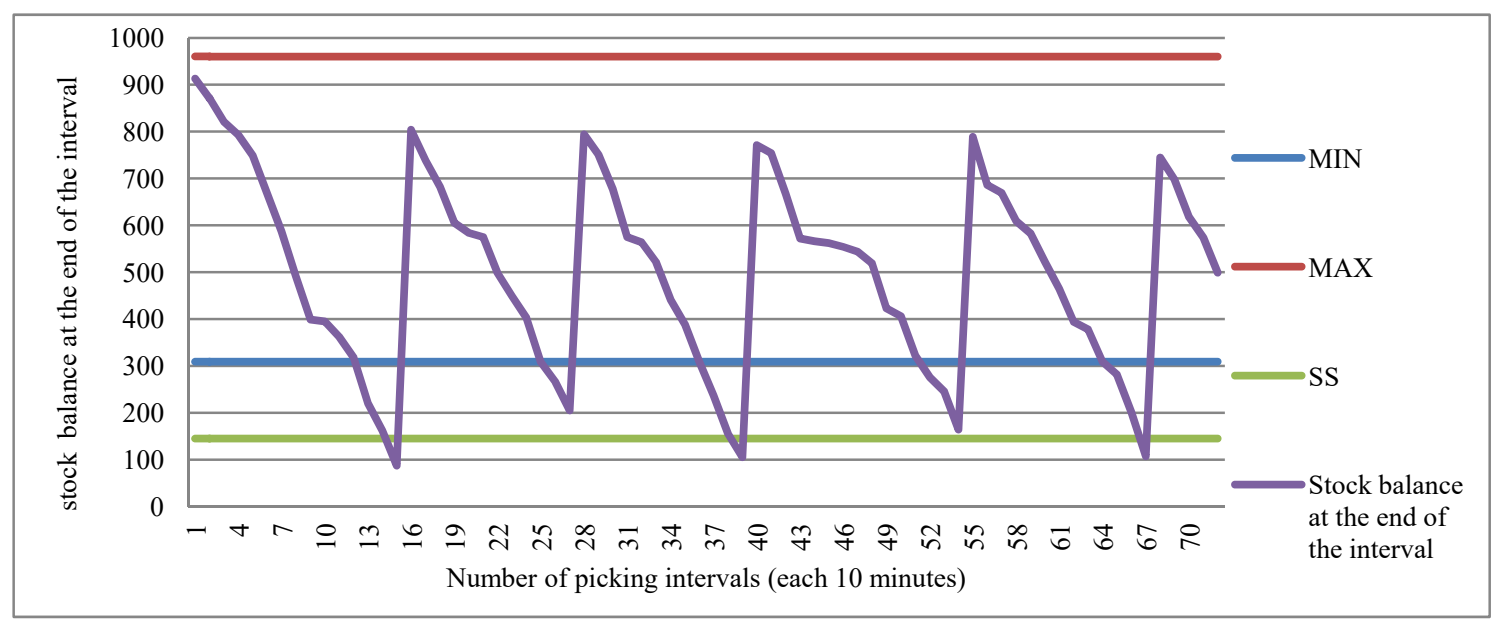

Figure 6. Stock balance at the end of the interval using the Min/Max stock control variant 2

Once again in order to make sure that the stock quantities are sufficient and the parameters of the Min/Max variant 2 work adequate, verification is carried out by changing the picking flow quantities. This means that the stock balance at the end of the time interval has been checked (Fig. 6).

The results of the simulation modelling illustrate that the balance of stock at the end of the time interval is sufficient and no stock outs occur. 


\section{Conclusions}

Both the Min/Max stock control variants have been verified by changing the picking flow quantities. Therefore, the statement that "using of Min/Max method for the replenishment of a picking location is sufficient for a stock - out of definite items not to occur" has been proved by the authors. The MIN level can be used as a solution for the determination of a critical level when the RCP starts, but the management of the stock control method at a picking address can be implemented by using the Min/Max variant 1 or Min/Max variant 2.

The obtained data evidently show that both stock control variants work equally well, as they result in no stock outs at the end of the time interval. In order to choose and adjust either of the above mentioned variants of Min/Max method, a comparable table has been created (Table 1). The application of RCP and Min/Max algorithms is necessary in case when replenishment will be allowed in an uninterrupted picking process. Otherwise, the replenishment will be realized outside of the picking process, and this will require several picking locations for each item (SKU) (Apsalons, 2015). The results of simulation modelling show that the Min/Max variant 1 is more suitable than the Min/Max variant 2 because the replenishment from SA to PA will be always done by full pallets, and no necessity will exist to move separate $\mathrm{HU}$ or CU. However, developing progressively the system $\mathrm{G} 2 \mathrm{M}$ - goods to man picking system, the Min/Max variant 2 could be used to ensure the replenishment from SA to PA to be realized by conveyors or automated systems.

Table 1. Characteristics of variants of MIN/MAX method for use of red card principle (RCP)

\begin{tabular}{|l|l|l|}
\hline Characteristic & MIN/MAX variant 1 & MIN/MAX variant2 \\
\hline MIN & $M I N_{k}=Q_{a} \cdot\left(R_{p}+\Delta \mathrm{t}\right) \cdot\left(1+k_{s s}\right)$ & $M I N_{k}=Q_{a} \cdot\left(R_{p}+\Delta \mathrm{t}\right) \cdot\left(1+k_{s s}\right)$ \\
\hline MAX & $\mathrm{MAX}=2 * \mathrm{MIN}$ & $\mathrm{MAX}=2 * \mathrm{Q}_{\mathrm{pll}}$ \\
\hline $\mathrm{SS}$ & $\mathrm{SS}=Q_{a} \cdot\left(R_{p}+\Delta \mathrm{t}\right) \cdot k_{s s}$ & $\mathrm{SS}=Q_{a} \cdot\left(R_{p}+\Delta \mathrm{t}\right) \cdot k_{s s}$ \\
\hline $\mathrm{Q}_{\mathrm{s}}$ & $\mathrm{Q}_{\mathrm{s}}=2 * \mathrm{Q}_{\mathrm{pll}}$ & $\mathrm{Q}_{\mathrm{s}}=2 * \mathrm{Q}_{\mathrm{pll}}$ \\
\hline $\mathrm{Q}_{\mathrm{j}}$ & $\mathrm{Q}_{\mathrm{j}}=\mathrm{Q}_{\mathrm{pll}}$ & $\mathrm{Q}_{\mathrm{j}}=\mathrm{MAX}-\mathrm{q}$ \\
\hline The number of replenishment in a day & comparably frequent & comparably rare \\
\hline $\begin{array}{l}\text { Replenishment has been realized by } \\
\text { full pallet }\end{array}$ & yes & no \\
\hline $\begin{array}{l}\text { Replenishment has been realized in } \\
\text { uninterrupted picking process }\end{array}$ & yes & yes \\
\hline
\end{tabular}

Finally, it is essentially to stress the Min/Max variant 2 requires to make replenishment less frequently than the variant 1 . This is explained with the replenishment volume of each item: in case of the Min/Max variant 1 the replenishment volume exceeds one pallet. Thus, the choice of both Min/Max variants to apply RCP is not unambiguous. It depends on such factors as picking systems, storing systems, the speed of the movements of goods, evaluation of total logistics cost, etc.

\section{References}

1. Andriansyah, R., Etman, P., Rooda, J. (2009) Simulation model of a single - server order picking workstation using aggregate process times. In: Advances in System Simulation, 2009. SIMUL '09. First International Conference on. Porto. E-ISBN: 978-0-7695-3773-3, INSPECT Accession Number: 10908795, pp $23-31$.

2. Apsalons, R. (2012) Logistikas centru pārvaldība. BURTENE, ISBN 978-9984-833-06-4, 189 lpp

3. Apsalons, R. (2015) The variants of small scale commodity picking system. In: RESEARCH and TECHNOLOGY - STEP into the FUTURE, 2015, Transport and Telecommunication Institute. Riga. ISSN 1691 - 2853, ISSN 1691 - 2861, pp 23 - 24.

4. Ballou, R.H. (1999) Business Logistics Management. Prentice - Hall Inc., 4-th edition, United States of America. ISBN: 0-13-081262-5, pp 681.

5. Frazelle, E.H. (2002) World-Class Warehousing and Material Handling. McGraw-Hill (India) Pvt Limited, ISNB 978-0-0713-7600-6, pp. 542. 
6. Inventory Management. https://msu.edu/course/prr/473/snapshot.afs/oldstuffInventory\%20Management.htm (05.10.2016).

7. King, P.L. (2011) Understanding safety stock and mastering its equations. July/August 2011. http://web.mit.edu/2.810/www/files/readings/King_SafetyStock.pdf (07.01.2017)

8. Koster, D. (1999) Efficient order batching methods in warehouses, Intelligent Journal of Production. Res., Vol. 37, No. 7, pp 1479-1504.

9. Lukinskiy, V., Lukinskiy, Vl. (2016) Evaluation of the influence of logistic operations reliability on the total costs of supply chain. In: Transport and telecommunication. Volume 17, No 4, pp. 307-313.

10. Monte Carlo Simulation. www.palisade.com/risk/monte_carlo_simulation.asp (05.10.2016).

11. Praude V. (2013) Logistika. BURTENE, ISBN 978-9984-833-095, 528 lpp.

12. Replenishment. Dematic Global website. www.dematic.com/en/supply-chain-solutions/by-supplychain-function/replenishment (05.10.2016).

13. Ruehrdanz, K. (2016) Pick face replenishment strategies. http://cdn.modexshow.com/seminars/assets2016/998.pdf (04.10.2016).

14. Sangam, V. (2010) Warehouse Key Performance Indicators. August 27, 2010. https://vijaysangamworld.wordpress.com/2010/08/27/warehouse-key-performance-indicators. (07.01.2017)

15. Tompkins, J.A., White, J.A., Bozer, Y.A., Tanchoto (2003) Facilities planning. 3-rd edition. John Wiley\&Sons, Inc. pp. 578-617.

16. Vermorel, J. (2009) Refreshing Min/Max inventory planning. Published on November 02, 2009. http://blog.lokad.com/journal/2009/11/2/refreshing-minmax-inventory-planning.html (04.10.2016).

17. Vermorel, J. (2012) Stock Replenishment Definition. Last revised January 2012. www.lokad.com/stock-replenishment-definition (07.01.2017). 